\title{
Pharmacokinetics and safety of posaconazole delayed-release tablets for invasive fungal infections
}

This article was published in the following Dove Press journal:

Clinical Pharmacology:Advances and Applications

23 December 2015

Number of times this article has been viewed

\section{Nathan PWiederhold \\ Departments of Pathology and Medicine/Infectious Diseases, University of Texas Health Science Center at San Antonio, South Texas Reference Laboratories, San Antonio, TX, USA}

\begin{abstract}
Posaconazole is a broad-spectrum triazole antifungal agent with potent activity against various pathogenic fungi, including yeast and moulds. Clinical studies have demonstrated that this agent is efficacious as prophylaxis against invasive fungal infections in patients at high risk, and may also be useful as salvage therapy against invasive aspergillosis and mucormycosis. However, the bioavailability of posaconazole following administration by oral suspension, which was the only formulation clinically available for many years, is highly variable and negatively influenced by several factors. Because of this, many patients had subtherapeutic or undetectable posaconazole levels when the oral suspension was used. To overcome this limitation, a delayedrelease tablet was developed and is now available for clinical use. Hot-melt extrusion technology is used to combine a $\mathrm{pH}$-sensitive polymer with posaconazole to produce a formulation that releases the drug in the elevated $\mathrm{pH}$ of the intestine where absorption occurs rather than in the low-pH environment of the stomach. This results in enhanced bioavailability and increased posaconazole exposure. Studies in healthy volunteers have demonstrated significantly higher and more consistent exposures with the tablet formulation compared to the oral suspension. In addition, pharmacokinetic parameters following administration of the tablets were not significantly affected by medications that raise gastric $\mathrm{pH}$ or increase gastric motility, and the tablets could also be administered without regard to food. Similar results have also been found in patients at high risk for invasive fungal infections who have received posaconazole tablets. The tablet formulation also appears to be well tolerated to date, although data regarding clinical efficacy are needed.
\end{abstract}

Keywords: posaconazole, pharmacokinetics, delayed-release tablet, antifungal prophylaxis, posaconazole oral suspension

\section{Introduction}

Posaconazole (Noxafil; Merck \& Co, Inc., Whitehouse Station, NJ, USA) is a broadspectrum antifungal agent that is used both as antifungal prophylaxis and treatment against invasive fungal infections. This azole antifungal agent, like the other members of this class, inhibits the enzyme $14 \alpha$-demethylase, which is responsible for the conversion of lanosterol to ergosterol, thereby inhibiting the biosynthesis of this cell membrane component. Posaconazole was the third extended-spectrum triazole to be approved for use against invasive fungal infections, following the availability of itraconazole and voriconazole. Similar to voriconazole, posaconazole has potent in vitro activity against yeasts, including Candida species, as well as Cryptococcus neoformans and Cryptococcus gattii. ${ }^{1,2}$ Both voriconazole and posaconazole also exhibit antifungal activity against Aspergillus species. ${ }^{3,4}$ However, unlike voriconazole, posaconazole does inhibit the
Correspondence: Nathan P Wiederhold Departments of Pathology and Medicine/ Infectious Diseases, University of Texas Health Science Center at San Antonio, 7703 Floyd Curl Drive, San Antonio, TX 78229, USA

Tel +I 2105674087

Email wiederholdn@uthscsa.edu

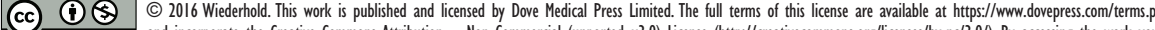

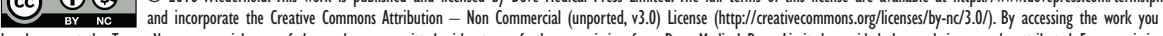
herebly acept the Terms. Non-commercial uses of the work are permitted without any further permission from Dove Medical Press Limited, provided the work is properly attributed. For permission for commercial use of this work, please see paragraphs 4.2 and 5 of our Terms (https://www.dovepress.com/terms.php). 
growth of members of the Order Mucorales, the causative agents of mucormycosis.

Posaconazole is clinically efficacious as prophylaxis against and in the treatment of invasive fungal infections. In two large, multicenter randomized trials, posaconazole was shown to be effective in preventing invasive fungal infections in highly immunocompromised patients, including hematologic malignancy patients with profound neutropenia, and allogeneic stem cell transplant recipients. In the setting of prolonged neutropenia secondary to chemotherapy in acute myelogenous leukemia (AML) or myelodysplastic syndrome, survival was significantly improved with posaconazole prophylaxis compared to fluconazole and itraconazole. ${ }^{6}$ Similarly, posaconazole prophylaxis reduced the number of breakthrough fungal infections and deaths due to invasive fungal infections compared to fluconazole in patients with severe graftversus-host disease (GVHD). ${ }^{5}$ Posaconazole has also been shown to be effective in open label studies as salvage therapy against invasive aspergillosis and against invasive mucormycosis..$^{7-9}$ Currently, posaconazole is indicated as prophylaxis against invasive fungal infections in high-risk patients as treatment against oropharyngeal candidiasis that is refractory to other therapies.

The utility of therapeutic drug monitoring is well established for several antimicrobial agents, and has been used for various antifungals, including the triazoles such as itraconazole, posaconazole, and voriconazole, and 5 -flucytosine. There are various reasons to perform therapeutic drug monitoring: to ensure that concentrations within biological fluids are above thresholds associated with response to therapy, as a means to assess the likelihood of toxicities with some drugs as concentrations above certain levels are associated with adverse effects, and to monitor patient adherence to therapeutic regimens. ${ }^{10}$ In recent years, significant attention has been focused on voriconazole serum concentrations, as several studies have reported associations between the trough concentrations that are achieved and both improved efficacy and toxicity. ${ }^{11-15}$ Studies have also reported positive associations between posaconazole bloodstream concentrations and clinical outcomes. In an open label study in which posaconazole was efficacious as salvage therapy against invasive aspergillosis, a relationship between posaconazole plasma concentrations and therapeutic efficacy was reported. ${ }^{7}$ The highest response rates $(\sim 75 \%)$ were observed among patients in the top quartile of posaconazole concentrations $(\geq 1,250 \mathrm{ng} / \mathrm{mL})$. Some studies have also reported that prophylactic efficacy may be enhanced in patients with plasma concentrations greater than $500 \mathrm{ng} / \mathrm{mL}$, while others have claimed that levels greater than $700 \mathrm{ng} / \mathrm{mL}$ are needed for this purpose. ${ }^{16-18}$ Others have suggested that concentrations in the tissue and epithelial lining fluids are more important than plasma concentrations for prophylactic effectiveness. ${ }^{19}$ Due to its lipophilic nature, posaconazole concentrates within the lipophilic regions of mammalian cell membranes, and this may prevent invasion of these cells by fungi and thereby prevent infection. However, many clinicians still perform therapeutic drug monitoring of posaconazole both when used as treatment and as prophylaxis.

\section{Pharmacokinetics of posaconazole oral suspension}

One of the main reasons for therapeutic drug monitoring of posaconazole has been the variable bioavailability following administration of the oral suspension, leading to inconsistent pharmacokinetics of this agent. When first approved for use in humans, the oral suspension was the only formulation that was available and continued to be so for many years. With this formulation, several studies reported that bloodstream concentrations were generally low, usually less than $700 \mathrm{ng} / \mathrm{mL}$, or undetectable in many patients..$^{7,16-18,20,21}$ In addition, significant interpatient variability with regard to posaconazole levels has been reported in clinical studies that evaluated the efficacy of oral suspension. ${ }^{5-7,22,23}$

Several factors are known to negatively affect the bioavailability of this formulation, which include the use of agents that raise gastric $\mathrm{pH}$, such as proton pump inhibitors (PPI), histamine2-receptor antagonists (H2RA), and antacids; nausea and vomiting; and agents that promote gastrointestinal motility. ${ }^{7,24}$ Although the long half-life of posaconazole ( $\sim 22-35$ hours) initially suggested that a loading dose followed by once-daily dosing may be feasible, saturable absorption was found to occur with the oral suspension formulation only at higher doses. ${ }^{22,25,26}$ In addition, a significant effect of food on the bioavailability of the oral suspension was observed. In healthy volunteers, a significant increase (300\%) in the overall exposure to posaconazole, as measured by the area under the concentration curve (AUC) over a 72-hour period, was observed when the oral suspension was administered with a high-fat meal as opposed to the fasted state. ${ }^{25}$ Similarly, a $168 \%$ increase in AUC was reported when the suspension was administered with a nonfat meal. Thus, it was required that the oral suspension of posaconazole be taken multiple times per day, preferably with a high-fat meal, 
in order to obtain consistent bloodstream concentrations needed for prophylaxis or therapy.

\section{Delayed-release tablet formulation and studies in healthy subjects}

Owing to the problems associated with the oral suspension, significant work was done to develop a new formulation that has improved bioavailability and more consistent pharmacokinetics. To this end, a new posaconazole tablet for oral administration was developed. This formulation, now available as $100 \mathrm{mg}$ tablets and approved for dosing as a $300 \mathrm{mg}$ twice-daily load on the first day and $300 \mathrm{mg}$ once-daily dose thereafter, consists of the active pharmaceutical ingredient, posaconazole, mixed with the $\mathrm{pH}$-sensitive polymer hypromellose acetate succinate (HPMCAS) via hotmelt extrusion technology. ${ }^{27,28}$ Hot-melt extrusion is a novel pharmaceutical formulation strategy used to produce drug formulations with enhanced bioavailability and solubility for poorly soluble drugs. Molecularly dispersed drug-polymer combinations, termed solid dispersions or solid solutions, that maintain the amorphous state of the drug by preventing crystallization are produced. ${ }^{29}$ This improves the solubility, which positively impacts the bioavailability of the drug. The $\mathrm{pH}$-sensitive polymer HPMCAS limits the release of posaconazole from the tablet in the presence of a highly acidic $\mathrm{pH}$, as encountered in the stomach, and releases the drug in the elevated $\mathrm{pH}$ environment of the intestine. ${ }^{27}$ In addition, it is thought that this polymer helps in preventing the recrystallization of posaconazole in the intestinal fluid. Together, these properties significantly enhance the oral bioavailability of the drug and result in improved exposures.

In a Phase I, single-center, open-label, two-part exploratory study, the pharmacokinetics of posaconazole following single-dose administration of two different tablet formulations and one capsule formulation were compared to that of the oral suspension in healthy volunteers. ${ }^{30}$ The tablets and capsule formulations each contained $100 \mathrm{mg}$ of posaconazole in a solid dispersion formed by dissolving posaconazole in a $\mathrm{pH}$-sensitive polymer matrix, HPMCAS and ascorbic acid, using hot-melt extrusion technology. In the first part, subjects received a single dose of the posaconazole formulations after a 10-hour fast, while in the second part the formulations were administered during a standardized high-fat breakfast. Under both fed and fasted conditions, both posaconazole tablets and capsule formulations resulted in significantly higher exposures than the oral suspension (Table 1). The higher exposures could be attributed to enhanced absorption of the drug, as the
Table I Pharmacokinetic parameters of posaconazole following a single $100 \mathrm{mg}$ dose of the oral suspension and two delayedrelease tablets and one capsule under fed and fasted conditions to healthy volunteers

\begin{tabular}{|c|c|c|c|c|c|c|}
\hline \multirow{2}{*}{$\begin{array}{l}\text { Parameter } \\
\text { Condition } \\
\end{array}$} & \multicolumn{2}{|c|}{$\begin{array}{l}\text { AUC } \\
(\mathrm{ng} \cdot \mathrm{h} / \mathrm{mL})\end{array}$} & \multicolumn{2}{|c|}{$\begin{array}{l}C_{\max } \\
(\mathrm{ng} / \mathrm{mL})\end{array}$} & \multicolumn{2}{|c|}{$\begin{array}{l}\text { Half-life } \\
\text { (hours) }\end{array}$} \\
\hline & Fasted & Fed & Fasted & Fed & Fasted & Fed \\
\hline Oral suspension & 2,970 & 8,470 & 84 & 243 & 29.2 & 25.1 \\
\hline Tablet A & 11,400 & $\mathrm{II}, 700$ & 385 & 327 & 26.1 & 23.7 \\
\hline Tablet B & 11,000 & 12,100 & 358 & 348 & 25 & 25.3 \\
\hline Capsule & 10,700 & 12,000 & 335 & 330 & 25.1 & 23.1 \\
\hline
\end{tabular}

Abbreviations: AUC, area under the concentration curve; $C_{\text {max }}$, peak concentration.

half-life was similar between the different formulations. The peak drug concentrations were also higher with the tablets and capsule formulations than with the oral suspension in the fasted condition, but were similar among all formulations when administered with food. Overall, the tablets and capsules also demonstrated less pharmacokinetic variability with smaller coefficients of variability for the peak and total exposures ( $25 \%$ for each) compared to the oral suspension (45\%-60\%). Consistent with previous results, posaconazole levels following administration of the oral suspension were significantly higher when administered with a high-fat meal compared to the fasted condition. ${ }^{24}$

Based on these results, one of the posaconazole delayedrelease tablet formulations was chosen, and a second Phase I study was conducted to evaluate the pharmacokinetics of this formulation with increasing single and multiple doses. ${ }^{30}$ In this study, the first dose of posaconazole was administered after an overnight fast, while the remaining doses were administered without regard to food. Dose-proportional increases in exposure were observed following single-dose administration of 200 and $400 \mathrm{mg}$ of posaconazole. Similarly, following multiple-dose administration of the tablet formulation for 8 days, dose-related increases in exposure were observed, as exposure increased in 1:1.9 and 1:1.8 ratios for days 1 and 14, respectively, when the dose was increased in a 1:2 ratio. The accumulation ratio (area under the concentration curve [AUC] on day 14 following multiple doses to AUC following single dose on day 1 ) was $\sim 3$ for the 200 and $400 \mathrm{mg}$ once-daily doses and 4.75 for the $200 \mathrm{mg}$ twice-daily group. Steady state was achieved after $\sim 7$ days of multiple dosing, with average concentrations of $1,310 \mathrm{ng} / \mathrm{mL}$ in the $200 \mathrm{mg}$ once-daily group and between 2,360 and 2,550 ng/mL in the $200 \mathrm{mg}$ twice-daily and $400 \mathrm{mg}$ once-daily groups. Overall, the posaconazole tablets were well tolerated with $48 \%$ of the subjects reporting at least one treatment-emergent adverse effect, including $17 \%$ in the placebo group. The most 
commonly reported adverse effects were increases in liver function tests $(24 \%)$, diarrhea (12\%), and headache $(2 \%)$. Although the increases in liver function tests were mild and without clinical sequelae, three subjects discontinued the therapy.

Since the effect of food on the bioavailability of the oral suspension is known, a randomized, two-period crossover study was conducted to evaluate the effect of a high-fat meal on the pharmacokinetics of posaconazole tablets in healthy volunteers following a single $300 \mathrm{mg}$ oral dose. ${ }^{31}$ Subjects either received a single dose after fasting for 10 hours or one administered 30 minutes after a high-fat meal. After a minimum washout of 7 days, subjects repeated the study but under the other condition. When tablets were administered after a high-fat meal, the exposure (AUC) and peak concentrations of posaconazole increased by $51 \%$ and $16 \%$, respectively, compared to when administered in the fasted state. Similarly, the posaconazole level at the 24 hour time point, representing a clinical trough, was also increased when administered with a high-fat meal (686 ng/mL vs $425 \mathrm{ng} / \mathrm{mL})$. These results reflect a modest effect of a high-fat meal on the pharmacokinetics of posaconazole, which is in contrast to the significant effect of a high-fat meal on the pharmacokinetics of the oral suspension. ${ }^{24}$ For the suspension formulation of posaconazole, the AUC was increased fourfold when the oral suspension was administered with a high-fat meal compared to fasted conditions, and was $\sim 2.6$ times greater when given with a nonfat meal or nutritional supplement.

In addition to evaluating the effects of food on the pharmacokinetics of the tablet formulation of posaconazole, another study determined the effects of medications that affect gastric $\mathrm{pH}$ and motility. Kraft et al conducted a randomized, five-way crossover, single-dose study in which all patients received one of the following: 1) a single dose of posaconazole $400 \mathrm{mg}$ (four $100 \mathrm{mg}$ tablets) alone; 2) posaconazole $400 \mathrm{mg}$ plus a single dose of antacid ( $2 \mathrm{~g}$ aluminum hydroxide/2 g magnesium hydroxide) administered together; 3) posaconazole $400 \mathrm{mg}$ administered 1 hour after a single $150 \mathrm{mg}$ dose of ranitidine; 4) posaconazole $400 \mathrm{mg}$ administered at the same time as the fifth and last dose of daily esomeprazole $40 \mathrm{mg}$; and 5) posaconazole $400 \mathrm{mg}$ administered at the same time as the last dose of metoclopramide (15 mg four times daily for 2 days). ${ }^{27}$ The pharmacokinetics of posaconazole, as measured by overall exposures (AUC values), peak concentrations, and half-lives, was similar when administered alone compared to when administered with these agents that affect gastric $\mathrm{pH}$ and motility. Peak concentrations ranged between 935 and 1,112 ng/mL, and
AUC values ranged from 38,513 to $42,468 \mathrm{~h} \cdot \mathrm{ng} / \mathrm{mL}$ under each of the conditions. The geometric mean ratios for AUC and $\mathrm{C}_{\max }$ ranged from 0.86 to 1.06 , indicating that there was no significant effect of gastric $\mathrm{pH}$ or motility on the pharmacokinetics of the posaconazole tablets. These results are in contrast to a previous study that found that coadministration of esomeprazole and metoclopramide significantly decreased the overall posaconazole exposure following the administration of oral suspension to healthy volunteers. ${ }^{24}$ Overall, the results in healthy volunteers were quite encouraging, as higher and more consistent posaconazole levels were achieved. In addition, this formulation did not appear to be significantly affected by the factors known to markedly reduce the bioavailability of the oral solution, which include administration in a fasted state and concomitant use of medications that raise the gastric $\mathrm{pH}$ or gastric motility.

\section{Pharmacokinetics and safety in Phase Ib and III studies in patients}

The first study to evaluate the pharmacokinetics of the new posaconazole tablets in patients was reported by Duarte et $\mathrm{al}^{32}$ In this prospective Phase Ib global, open-label, dose-escalation study, patients undergoing chemotherapy for AML or myelodysplastic syndrome with prolonged neutropenia were assigned to one of two sequential dosing cohorts. The first dosing cohort included 20 patients who received posaconazole tablets at a dose of $200 \mathrm{mg}$ once daily. After review of the findings of the first cohort, the posaconoazole dose of the second cohort, which consisted of 34 patients, was increased to $300 \mathrm{mg}$ once daily. In each cohort, the dose was administered twice on the first day of therapy, and posaconazole tablets were administered without regard to food intake during the course of the study. After 2 days of dosing, the mean posaconazole trough concentration in the $300 \mathrm{mg}$ dosing cohort was already greater than the target level set for the study, ie, $500 \mathrm{ng} / \mathrm{mL}$. This minimum target level was chosen as a posaconazole MIC of $500 \mathrm{ng} / \mathrm{mL}$ inhibits $90 \%$ of Aspergillus species isolated from clinical infections. ${ }^{4}$ By day 8 , the mean posaconazole $\mathrm{C}_{\text {avg }}$ values were $951 \mathrm{ng} / \mathrm{mL}$ and $1,460 \mathrm{ng} / \mathrm{mL}$ in the 200 and $300 \mathrm{mg}$ dosing cohorts, respectively, with steady state being achieved between days 6 and 8 . Overall, 97\% of the patients in the $300 \mathrm{mg}$ cohort achieved average concentration values within the desired lower and upper exposure limits of 500-2,500 $\mathrm{ng} / \mathrm{mL}$. In the $200 \mathrm{mg}$ cohort, $79 \%$ of patients achieved average concentration values within this range. Only one patient in the study exceeded the desired upper exposure limit $(2,680 \mathrm{ng} / \mathrm{mL})$. 
The safety profile of posaconazole tablets was also evaluated in this study. All patients experienced at least one treatment-emergent adverse effect, with adverse effects judged to be treatment-related in $50 \%$ and $41 \%$ of patients in the 200 and $300 \mathrm{mg}$ cohorts, respectively. Gastrointestinal adverse effects were the most commonly reported adverse effects that were treatment-related ( $25 \%$ in the $200 \mathrm{mg}$ cohort and $32 \%$ in the $300 \mathrm{mg}$ cohort). However, the percentage of patients who discontinued therapy due to treatment-emergent adverse effects was only $15 \%$ in the $200 \mathrm{mg}$ cohort and $21 \%$ in the $300 \mathrm{mg}$ cohort. Other commonly reported treatmentrelated adverse effects included diarrhea, rash, abdominal pain, and vomiting. There were no reports of safety concerns due to elevated liver function tests or QTc prolongation (>500 ms) in this study. Based on the concentration and exposure data as well as the overall safety, the $300 \mathrm{mg}$ dose was chosen for the Phase III study.

In the open-label, multicenter Phase III study, the pharmacokinetics of the delayed-release posaconazole tablets was evaluated in 107 neutropenic AML/mylodysplasia patients and 79 patients who were receiving immunosuppressive therapy for the prevention of GVHD following hematopoietic stem cell transplantation. ${ }^{33}$ To date, this study has only been reported in the abstract form. The tablets were administered for 28 days without regard to food, and the target average concentration limits were $\geq 500$ to $<3,750 \mathrm{ng} / \mathrm{mL}$. This target was achieved in $96 \%$ of patients, with only one patient not achieving the lower limit of $500 \mathrm{ng} / \mathrm{mL}$ and four patients exceeding $3,750 \mathrm{ng} / \mathrm{mL}$. The average concentration values of posaconazole also correlated strongly with trough levels $(r=0.92)$, and only nausea and diarrhea were reported as common adverse effects ( $11 \%$ and $8 \%$, respectively). Thus, the pharmacokinetic and safety results from the clinical studies conducted in patients prior to the approval of this formulation were also encouraging, with higher and more consistent posaconazole levels achieved similar to those observed in healthy volunteers.

\section{Post-approval real-world experiences}

Following the availability of the delayed-release oral tablet in December 2013, several single-center reports have been published documenting the experience with this formulation. One of the first reports was a crossover study of patients who were switched from oral suspension to oral tablet formulation. ${ }^{34} \mathrm{In}$ this study, conducted at the University of Texas MD Anderson Cancer Center, 12 leukemia patients, five of whom had undergone hematopoietic stem cell transplantation, including three who suffered from GVHD, were included. In all, 21 suspension and 30 tablet formulations were included, and the target posaconazole concentration for prophylaxis $(>700 \mathrm{ng} / \mathrm{mL})$ was achieved in $97 \%$ of serum concentrations following tablet administration compared to $57 \%$ with the oral suspension. Similarly, the target level $(>1,000 \mathrm{ng} / \mathrm{mL})$ required for the drug to be used as treatment was achieved in $83 \%$ with the tablet and $24 \%$ with the oral suspension. Comparative measurements were available in nine patients, and the median posaconazole serum concentration was significantly higher after the switch to the tablet $(1,910 \mathrm{ng} / \mathrm{mL})$ compared to that achieved during the period when oral suspension was given (748 ng/mL). Factors known to cause reductions in posaconazole serum levels with the oral suspension, such as GVHD, diarrhea, and acid suppression, were not associated with reductions in the median posaconazole concentration after switch to the tablets. Also, the tablet formulation was well tolerated in this study. Mild, asymptomatic increases in liver function tests were observed following the switch to posaconazole tablets in five of the nine patients who had normal baseline values, and this primarily manifested as elevations in total bilirubin. However, the liver enzymes returned to normal within 3 weeks despite continued administration.

In a larger retrospective, single-center study conducted at the Mayo Clinic, which included a more diverse group of patients, Durani et al compared posaconazole concentrations achieved in those who were administered the oral suspension to patients who received the delayed-release tablet. ${ }^{35}$ All patients who were initiated on posaconazole and had their serum levels measured between January 2012 and July 2014 were included. This included post-allogeneic stem cell transplant recipients, those with hematologic malignancies, and solid organ transplant patients. The primary and secondary outcomes were the proportions of initial posaconazole levels greater than 700 and $1,250 \mathrm{ng} / \mathrm{mL}$, respectively. Ninety-three patients were included in the study, including 63 who had an initial posaconazole level measured between 5 and 14 days after the initiation of therapy. Among the 63 patients with levels determined during this timeframe (20 who received the tablet and 43 the oral suspension), a significantly higher proportion of patients who received the tablet formulation achieved levels greater than $700 \mathrm{ng} /$ $\mathrm{mL}$ versus those who received the oral suspension $(90 \%$ vs $58 \%$, respectively; $P=0.011$ ). Likewise, a significantly higher proportion of patients in the tablet cohort achieved levels greater than $1,250 \mathrm{ng} / \mathrm{mL}$ ( $75 \%$ vs $33 \% ; P=0.002$ ), and median posaconazole concentrations were also significantly higher in the tablet cohort compared to those who received 
the oral suspension $(1,655 \mathrm{ng} / \mathrm{mL}$ vs $798 \mathrm{ng} / \mathrm{mL} ; P=0.004)$. Posaconazole levels in patients who received the tablet formulation were not affected by acid suppression, as all patients in this cohort received acid-suppressing medications and $90 \%$ achieved the primary therapeutic level of $700 \mathrm{ng} /$ $\mathrm{mL}$. Interestingly, median posaconazole levels were higher in patients whose levels were measured between 8 and 14 days after therapy was initiated compared to those in whom levels were measured between 5 and 7 days, suggesting that steady state was not yet achieved in the earlier time period.

Miceli et al conducted a retrospective chart review of AML and hematopoietic stell cell transplant recipients who received posaconazole tablets as antifungal prophylaxis at the University of Michigan Health System between February and May 2014. ${ }^{36}$ In total, 28 patients, 22 who had received chemotherapy for AML and six stem cell transplant recipients, were included. The mean serum trough level on day 5 of therapy was $1,190 \mathrm{ng} / \mathrm{mL}$ (range 360-2,500 ng/mL). The mean posaconazole plasma concentration in the 23 patients who were receiving either a PPI or $\mathrm{H} 2 \mathrm{~A}$ receptor antagonist $(1,110 \mathrm{ng} / \mathrm{mL})$ was not significantly different from those who did not receive one of these medications $(1,620 \mathrm{ng} / \mathrm{mL})$. However, the mean posaconazole concentration was significantly lower in the five patients who had diarrhea $(650 \mathrm{ng} / \mathrm{mL})$ compared to those who did not $(1,310 \mathrm{ng} / \mathrm{mL} ; P=0.0002)$, and only two of the five patients with diarrhea achieved the target concentration of $700 \mathrm{ng} / \mathrm{mL}$. The effects of patient weight and body mass index (BMI) were also evaluated in this study. Mean posaconazole trough concentrations were significantly lower in patients who weighted at least $90 \mathrm{~kg}$ $(740 \mathrm{ng} / \mathrm{mL})$ or had a BMI of 30 or higher $(890 \mathrm{ng} / \mathrm{mL})$. The potential relationship between elevated weight and BMI and lower posaconazole concentrations is not unexpected as pathophysiologic changes that are seen in these patients, such as protein binding, cardiac output, and hepatic metabolism, are known to alter the pharmacokinetics of other drugs. ${ }^{37} \mathrm{In}$ addition, as posaconazole is highly lipophilic, distribution to the adipose tissue of obese patients may change the distribution resulting in lower serum concentration. Although the effects of fasting were also evaluated in this study, no conclusions could be made as two of the three patients who were fasting also had diarrhea.

The most recent experience was reported from the West Virginia University Hospitals by Cumpston et al, who conducted a retrospective analysis of posaconazole concentrations in patients who received the suspension or the tablet formulation as prophylaxis. ${ }^{38}$ Patients included those with AML or high-risk myelodysplastic syndrome undergoing systemic therapy and expected to have an absolute neutrophil count of $<500 / \mathrm{uL}$ for $7-10$ days. One hundred eighteen patients received the suspension $(600-800 \mathrm{mg} /$ day in divided doses) between February 2008 and December 2013, and 32 patients received posaconazole tablets ( $300 \mathrm{mg}$ twice on the first day and $300 \mathrm{mg} /$ day thereafter) between January and December of 2014. Posaconazole levels were obtained at a median of 8 days and 7 days after the start of prophylaxis in the suspension and tablet groups, respectively. Overall, the median steady-state concentration in patients who received tablets $(1,740 \mathrm{ng} / \mathrm{mL}$, range $662-3,350 \mathrm{ng} / \mathrm{mL})$ was significantly higher than in the group that received the suspension (390 ng/mL, range 51-1,870 ng/mL; $P<0.0001$ ), and a significantly higher percentage of patients in the tablet group achieved the target steady-state concentration of $700 \mathrm{ng} / \mathrm{mL}$ ( $97 \%$ vs $17 \% ; P<0.0001)$. Acid suppression did not appear to affect posaconazole concentrations in those who received the tablet, as significantly higher levels were observed in patients receiving this formulation with either a PPI or H2A receptor antagonist compared to the oral suspension. Overall, toxicities did not appear to be different between the groups, with clinically significant hepatotoxicity occurring in one patient in each group, and grade 2 or higher prolongations in the QTc interval were observed in $9 \%$ and $17 \%$ in the suspension and tablet groups, respectively.

\section{Clinical efficacy and role of therapeutic drug monitoring}

The results from the Phase Ib and III clinical trials as well as the various single-center reports demonstrate that, indeed, the pharmacokinetics of posaconazole are significantly improved with the delayed-release tablet formulation. Higher exposures with less variability were consistently demonstrated in these studies. In addition, the bioavailability of posaconazole with this formulation does not appear to be significantly affected by food or the concomitant use of medications that raise gastric $\mathrm{pH}$ or speed gastric motility. Although the improved pharmacokinetics of posaconazole tablets is expected to improve clinical outcomes in patients, there are few clinical data at this time to support this. The studies that have been conducted to date with the tablet have focused on the pharmacokinetics and safety of this formulation. While few breakthrough invasive fungal infections were observed in these reports, the studies were not designed to evaluate efficacy, either as prophylaxis or as treatment for invasive fungal infections.

One of the main advantages of the new tablet formulation may be the reduced need for therapeutic drug monitoring of 
posaconazole. As previously described, numerous factors influenced the bioavailability of the oral suspension with many patients having low or undetectable levels..$^{17,18,20,21}$ For this reason, posaconazole concentrations were frequently monitored in many patients. While this was justified with the oral suspension due to the significant variability that was observed along with the association between efficacy and certain threshold levels, it is unknown if frequent therapeutic drug monitoring will be needed with the tablet formulation. The results from the Phase $\mathrm{Ib}$ and III studies and the reports from different institutions suggest that routine measurement of posaconazole levels may not be needed due to the improved pharmacokinetics of the delayed-release tablets. However, there still may be a need in certain circumstances, such as in patients with severe diarrhea, ${ }^{36}$ or as a means to determine reasons for clinical failures. Therapeutic drug monitoring may also be still needed in patients with invasive fungal infections where higher levels are warranted. The need for higher posaconazole concentrations in this setting has previously been demonstrated in patients with invasive aspergillosis and is currently recommended in the antifungal therapeutic drug monitoring guidelines from the British Society for Medical Mycology. ${ }^{7,39}$

When low plasma concentrations are observed, clinicians may either switch to the new intravenous formulation of posaconazole or consider increasing the dose of the oral tablet. However, the safety of higher doses of posaconazole is still unknown. In one recent case report, nausea, decreased enteral intake, fatigue, musculoskeletal pain, and progressive anemia were observed in a patient with a posaconazole level of $9,500 \mathrm{ng} / \mathrm{mL}$ secondary to inadvertently being prescribed a dose of $400 \mathrm{mg}$ twice daily for 2 months. ${ }^{40} \mathrm{In}$ another report, seven of 17 patients with posaconazole levels greater than $2,000 \mathrm{ng} / \mathrm{mL}$ following administration of the delayed-release tablets experienced increases in liver function tests greater than two times the upper limit of normal or their baseline levels. ${ }^{41}$

\section{Conclusion}

The new delayed-release tablet of posaconazole represents a significant formulation improvement over the oral suspension of this azole antifungal agent. Higher and more consistent posaconazole exposures have been reported both in healthy volunteers and in patients at high risk for invasive fungal infections. In addition, many of the factors that negatively affected the bioavailability of the oral suspension, such as medications that raised the gastric $\mathrm{pH}$ or increased gastric motility and the need for frequent administration with food, do not appear to significantly influence the bioavailability and exposure following administration of the tablet formulation. Data to date also suggest that the tablet is well tolerated with few clinically significant adverse effects. Further studies are needed in order to determine the efficacy of the tablet formulation as prevention against and treatment for invasive fungal infections.

\section{Disclosure}

NPW has received research support from Astellas, bioMerieux, Dow, F2G, Merck, Merz, Revolution Medicines, and Viamet, and has served on advisory boards for Astellas, Merck, Toyama, and Viamet. The author reports no other conflicts of interest in this work.

\section{References}

1. Thompson GR 3rd, Wiederhold NP, Sutton DA, Fothergill A, Patterson TF. In vitro activity of isavuconazole against Trichosporon, Rhodotorula, Geotrichum, Saccharomyces and Pichia species. J Antimicrob Chemother. 2009;64(1):79-83.

2. Thompson GR 3rd, Wiederhold NP, Fothergill AW, Vallor AC, Wickes BL, Patterson TF. Antifungal susceptibilities among different serotypes of Cryptococcus gattii and Cryptococcus neoformans. Antimicrob Agents Chemother. 2009;53(1):309-311.

3. Nagappan V, Deresinski S. Reviews of anti-infective agents: posaconazole: a broad-spectrum triazole antifungal agent. Clin Infect Dis. 2007;45(12):1610-1617.

4. Pfaller MA, Messer SA, Hollis RJ, Jones RN, Group SP. Antifungal activities of posaconazole, ravuconazole, and voriconazole compared to those of itraconazole and amphotericin B against 239 clinical isolates of Aspergillus spp. and other filamentous fungi: report from SENTRY Antimicrobial Surveillance Program, 2000. Antimicrob Agents Chemother. 2002;46(4):1032-1037.

5. Ullmann AJ, Lipton JH, Vesole DH, et al. Posaconazole or fluconazole for prophylaxis in severe graft-versus-host disease. N Engl J Med. 2007; 356(4):335-347.

6. Cornely OA, Maertens J, Winston DJ, et al. Posaconazole vs fluconazole or itraconazole prophylaxis in patients with neutropenia. $N$ Engl J Med. 2007;356(4):348-359.

7. Walsh TJ, Raad I, Patterson TF, et al. Treatment of invasive aspergillosis with posaconazole in patients who are refractory to or intolerant of conventional therapy: an externally controlled trial. Clin Infect Dis. 2007;44(1):2-12.

8. Greenberg RN, Mullane K, van Burik JA, et al. Posaconazole as salvage therapy for zygomycosis. Antimicrob Agents Chemother. 2006;50(1): 126-133.

9. van Burik JA, Hare RS, Solomon HF, Corrado ML, Kontoyiannis DP. Posaconazole is effective as salvage therapy in zygomycosis: a retrospective summary of 91 cases. Clin Infect Dis. 2006;42(7): e61-e65.

10. Summers KK, Hardin TC, Gore SJ, Graybill JR. Therapeutic drug monitoring of systemic antifungal therapy. J Antimicrob Chemother. 1997;40(6):753-764.

11. Smith J, Safdar N, Knasinski V, et al. Voriconazole therapeutic drug monitoring. Antimicrob Agents Chemother. 2006;50(4):1570-1572.

12. Pascual A, Calandra T, Bolay S, Buclin T, Bille J, Marchetti O. Voriconazole therapeutic drug monitoring in patients with invasive mycoses improves efficacy and safety outcomes. Clin Infect Dis. 2008; 46(2):201-211.

13. Imhof A, Schaer DJ, Schanz U, Schwarz U. Neurological adverse events to voriconazole: evidence for therapeutic drug monitoring. Swiss Med Wkly. 2006;136(45-46):739-742. 
14. Tan K, Brayshaw N, Tomaszewski K, Troke P, Wood N. Investigation of the potential relationships between plasma voriconazole concentrations and visual adverse events or liver function test abnormalities. J Clin Pharmacol. 2006;46(2):235-243.

15. Pascual A, Csajka C, Buclin T, et al. Challenging recommended oral and intravenous voriconazole doses for improved efficacy and safety: population pharmacokinetics-based analysis of adult patients with invasive fungal infections. Clin Infect Dis. 2012;55(3):381-390.

16. Jang SH, Colangelo PM, Gobburu JV. Exposure-response of posaconazole used for prophylaxis against invasive fungal infections: evaluating the need to adjust doses based on drug concentrations in plasma. Clin Pharmacol Ther. 2010;88(1):115-119.

17. Shields RK, Clancy CJ, Vadnerkar A, et al. Posaconazole serum concentrations among cardiothoracic transplant recipients: factors impacting trough levels and correlation with clinical response to therapy. Antimicrob Agents Chemother. 2011;55(3):1308-1311.

18. Dolton MJ, Ray JE, Chen SC, Ng K, Pont L, McLachlan AJ. Multicenter study of posaconazole therapeutic drug monitoring: exposure-response relationship and factors affecting concentration. Antimicrob Agents Chemother. 2012;56(11):5503-5510.

19. Campoli P, Perlin DS, Kristof AS, White TC, Filler SG, Sheppard DC. Pharmacokinetics of posaconazole within epithelial cells and fungi: insights into potential mechanisms of action during treatment and prophylaxis. J Infect Dis. 2013;208(10):1717-1728.

20. Wiederhold NP, Pennick GJ, Dorsey SA, et al. A reference laboratory experience of clinically achievable voriconazole, posaconazole, and itraconazole concentrations within the bloodstream and cerebral spinal fluid. Antimicrob Agents Chemother. 2014;58(1):424-431.

21. Thompson GR 3rd, Rinaldi MG, Pennick G, Dorsey SA, Patterson TF, Lewis JS 2nd. Posaconazole therapeutic drug monitoring: a reference laboratory experience. Antimicrob Agents Chemother. 2009;53(5): 2223-2224.

22. Ullmann AJ, Cornely OA, Burchardt A, et al. Pharmacokinetics, safety, and efficacy of posaconazole in patients with persistent febrile neutropenia or refractory invasive fungal infection. Antimicrob Agents Chemother. 2006;50(2):658-666.

23. Gubbins PO, Krishna G, Sansone-Parsons A, et al. Pharmacokinetics and safety of oral posaconazole in neutropenic stem cell transplant recipients. Antimicrob Agents Chemother. 2006;50(6):1993-1999.

24. Krishna G, Moton A, Ma L, Medlock MM, McLeod J. Pharmacokinetics and absorption of posaconazole oral suspension under various gastric conditions in healthy volunteers. Antimicrob Agents Chemother. 2009; 53(3):958-966.

25. Courtney R, Wexler D, Radwanski E, Lim J, Laughlin M. Effect of food on the relative bioavailability of two oral formulations of posaconazole in healthy adults. Br J Clin Pharmacol. 2004;57(2):218-222.

26. Courtney R, Pai S, Laughlin M, Lim J, Batra V. Pharmacokinetics, safety, and tolerability of oral posaconazole administered in single and multiple doses in healthy adults. Antimicrob Agents Chemother. 2003;47(9):2788-2795.

27. Kraft WK, Chang PS, van Iersel ML, Waskin H, Krishna G, Kersemaekers WM. Posaconazole tablet pharmacokinetics: lack of effect of concomitant medications altering gastric $\mathrm{pH}$ and gastric motility in healthy subjects. Antimicrob Agents Chemother. 2014;58(7): 4020-4025.
28. Krishna G, Ma L, Martinho M, Preston RA, O’Mara E. A new solid oral tablet formulation of posaconazole: a randomized clinical trial to investigate rising single- and multiple-dose pharmacokinetics and safety in healthy volunteers. J Antimicrob Chemother. 2012;67(11): 2725-2730.

29. Fule R, Amin P. Hot melt extruded amorphous solid dispersion of posaconazole with improved bioavailability: investigating drugpolymer miscibility with advanced characterisation. Biomed Res Int. 2014;2014:146781.

30. Krishna G, Ma L, Martinho M, O’Mara E. Single-dose phase I study to evaluate the pharmacokinetics of posaconazole in new tablet and capsule formulations relative to oral suspension. Antimicrob Agents Chemother. 2012;56(8):4196-4201.

31. Kersemaekers WM, Dogterom P, Xu J, et al. Effect of a high-fat meal on the pharmacokinetics of 300-milligram posaconazole in a solid oral tablet formulation. Antimicrob Agents Chemother. 2015;59(6): 3385-3389.

32. Duarte RF, Lopez-Jimenez J, Cornely OA, et al. Phase 1b study of new posaconazole tablet for prevention of invasive fungal infections in high-risk patients with neutropenia. Antimicrob Agents Chemother. 2014;58(10):5758-5765.

33. Cornely OA, Duarte RF, Haider S, et al. Phase 3 pharmacokinetics (PK) and safety of posaconazole (POS) tablet in patients at risk for invasive fungal infection. Presented at: 23rd European Congress on Clinical Microbiology and Infectious Diseases; 2013; Berlin, Germany.

34. Jung DS, Tverdek FP, Kontoyiannis DP. Switching from posaconazole suspension to tablets increases serum drug levels in leukemia patients without clinically relevant hepatotoxicity. Antimicrob Agents Chemother. 2014;58(11):6993-6995.

35. Durani U, Tosh PK, Barreto JN, Estes LL, Jannetto PJ, Tande AJ. Retrospective comparison of posaconazole levels in patients taking the delayed-release tablet versus the oral suspension. Antimicrob Agents Chemother. 2015;59(8):4914-4918.

36. Miceli MH, Perissinotti AJ, Kauffman CA, Couriel DR. Serum posaconazole levels among haematological cancer patients taking extended release tablets is affected by body weight and diarrhoea: single centre retrospective analysis. Mycoses. 2015;58(7):432-436.

37. Hanley MJ, Abernethy DR, Greenblatt DJ. Effect of obesity on the pharmacokinetics of drugs in humans. Clin Pharmacokinet. 2010;49(2): 71-87.

38. Cumpston A, Caddell R, Shillingburg A, et al. Superior Serum Concentrations with Posaconazole Delayed-Release Tablets Compared to Suspension Formulation in Hematological Malignancies. Antimicrob Agents Chemother. 2015;59(8):4424-4428.

39. Ashbee HR, Barnes RA, Johnson EM, Richardson MD, Gorton R, Hope WW. Therapeutic drug monitoring (TDM) of antifungal agents: guidelines from the British Society for Medical Mycology. J Antimicrob Chemother. 2014;69(5):1162-1176.

40. Martino J, Fisher BT, Bosse KR, Bagatell R. Suspected posaconazole toxicity in a pediatric oncology patient. Pediatr Blood Cancer. 2015;62(9):1682.

41. Pettit NN, Steinbeck JL, Han Z, de la Cruz J, Landon E, Pisano J. Posaconazole (PCZ) tablet formation therapeutic drug monitoring (TDM) and toxicity analysis. Poster presented at: 54th Interscience Conference on Antimicrobial Agents and Chemotherapy; September 5-9; 2014; Washington, DC.
Clinical Pharmacology: Advances and Applications

\section{Publish your work in this journal}

Clinical Pharmacology: Advances and Applications is an international, peer-reviewed, open access journal publishing original research, reports, reviews and commentaries on all areas of drug experience in humans. The manuscript management system is completely online and includes a very quick and fair peer-review system, which is all easy to use.
Dovepress

Visit http://www.dovepress.com/testimonials.php to read real quotes from published authors. 